\title{
Current practice of French health professionals regarding Japanese encephalitis
}

$$
\text { vaccination }
$$

\section{Pratiques vaccinales contre l'encéphalite japonaise en France}

\section{Amat ${ }^{1}$, AP Bellanger ${ }^{2,3}$, F Bozon ${ }^{4}$, R Léger ${ }^{1}$, H Gbaguidi-Haore ${ }^{5}$, P Marguet $^{1}$}

${ }^{1}$ Emergency Department, Regional Hospital of Pontarlier, France

${ }^{2}$ Department of Parasitology-Mycology, University Hospital of Besançon, France

${ }^{3}$ CNRS-University of Franche-Comte/ UMR 6249 Chrono-environment, Besançon, France

${ }^{4}$ Infectious and Tropical Disease Department, University Hospital of Besançon, France

${ }^{5}$ Infection Control Department, University Hospital of Besançon, France

*Corresponding author: Anne-Pauline Bellanger, Department of Parasitology-Mycology, Jean

Minjoz University Hospital, 25030 Besançon, France.

Fax $33(0) 370632364$. Tel $33(0) 370632351$

Email address: apbellanger@chu-besancon.fr

\section{Acknowledgements}

We would like to thank Pamela Albert for editorial assistance.

\section{Declaration of interests}

The authors declare no conflict of interests. 
Mots clés : encéphalite japonaise, vaccination, centre de vaccination

Keywords: Japanese encephalitis, vaccination, vaccination center

\section{Contribution of authors}

CA was in charge of the study, which was the topic of her thesis. APB wrote the article.

FB provided her expertise on the subject. RL designed the questionnaire. HGH performed the statistical analysis. PM designed the study and provided his expertise on the subject. 


\section{Résumé}

Objectifs. L'encéphalite japonaise est une maladie rare mais grave, qui représente un risque pour les voyageurs qui se rendent en zones d'endémie. Le risque de développer une encéphalite japonaise est inférieur à $1 \%$ mais la maladie peut être létale dans $30 \%$ des cas. II n'existe pas de traitement spécifique mais un vaccin est disponible. L'objectif était de réaliser un état des lieux des pratiques vaccinales contre l'encéphalite japonaise en France.

Méthodes. Des questionnaires ont été envoyés par email à des professionnels de santé exerçant dans des centres de vaccination. La participation était anonyme et bénévole. En plus des informations socio-démographiques, le questionnaire comportait des questions à choix multiples et un cas concret.

Résultats. Le taux de réponse était de $38.5 \%$. La majorité des participants travaillaient depuis au moins trois ans en centre de vaccination et ont déclaré être favorables au vaccin de l’encéphalite japonaise. Les réticences déclarées concernaient le prix du vaccin et la difficulté à évaluer le risque d'exposition. Le protocole rapide était largement privilégié en métropole ( $p<0.05$, test exact de Fisher). Les voyages en Asie du sud-est et le fait de voyager en tant que routard étaient considérés comme des situations à risque. La vaccination était proposée toute l’année. La majorité des participants n'auraient pas proposé la vaccination pour le cas concret du questionnaire.

Conclusions. Les professionnels de santé français sont globalement favorables à la vaccination contre l'encéphalite japonaise. Cependant, ils rencontrent des difficultés au quotidien pour estimer au plus juste le risque d'exposition. 


\section{Abstract}

Objective. Japanese encephalitis (JE) is a rare but severe disease. It is a potential threat for people traveling to endemic areas. The risk of developing JE is low $(<1 \%)$, but the associated case fatality is high (30\%). There is no specific treatment for JE, but a vaccine is available. We performed an observational survey to assess practices of French health professionals regarding JE vaccination.

Methods. Standardized questionnaires were sent by email to a sample of French health professionals practicing in vaccination centers. Participation was on a voluntary and anonymous basis. The questionnaires requested socio-demographic details, and included multiple choice questions.

Results. The response rate was $38.5 \%$. Most participating health professionals had been working for more than three years in a vaccination center and declared not to be reluctant to perform JE vaccination. Reluctance was mostly based on the vaccine cost and on the difficulty to properly assess the risk for patients. The rapid protocol was largely preferred except in the overseas regions ( $p<0.05$, Fisher's exact test). Traveling to South Asia and backpacking were considered at-risk conditions. Participants proposed the vaccination all year round. Most participants would not have proposed the JE vaccination for the concrete case outlined in the questionnaire.

Conclusions. French health professionals are globally favorable to JE vaccination. However, assessing the risk of exposure is difficult in routine practice. 


\section{Introduction}

Japanese encephalitis (JE) is caused by a virus of the Flavivirus genus (Flaviviridae family) and is transmitted by Culex mosquitoes. The annual number of JE cases is estimated at 67,000 [1]. Although clinical JE develops in less than $1 \%$ of infected individuals, its case fatality is about $30 \%$ and it is associated with a risk of permanent neurological damage $(30 \%-50 \%)[1,2]$.

Individual risk factors usually taken into consideration are the destination, duration and season of travel, itinerary, type of accommodations and activities. However, travel-associated JE may occur among travelers of any profile.

No specific treatment is available for JE, but the disease is preventable by vaccination since IXIARO, an inactivated Vero cell culture-derived JE vaccine, was licensed in 2009 by the Center for Disease Control [3]. French guidelines recommend JE vaccination for adults traveling to endemic areas with extensive outdoor activities, irrespective of the duration of the stay [4]. However, health professionals have difficulties apprehending indications for JE vaccination. An observational survey was undertaken in 2016 to assess the practice of French health professionals regarding JE vaccination.

\section{Methods}

An observational survey was conducted in 2016 as follows: standardized questionnaires were sent by email to a sample of French health professionals practicing in vaccination centers (one per center). They were asked to participate on a voluntary and anonymous basis. The addresses of vaccination centers were obtained from various sources: the website "mesvaccins.net", the website of the Travel Medicine Society (http://www.medecinevoyages.fr/), and from a previous survey on yellow fever vaccination in the elderly [5]. 
The questionnaire was designed to be short to encourage participation. It was made up of two parts: 1) five questions requesting sociodemographic details (sex, age group, number of years of practice in the vaccination center, geographical area of practice, and profession), 2) 10 practice-related questions (estimated number of JE vaccinations per year, reluctance to perform JE vaccinations, estimated frequency of JE vaccination refusal, use of the rapid protocol, booster vaccination and delay, observed adverse events, criteria taken into account to propose JE vaccination such as destination, type of travel, rainy season, and a concrete case was proposed).

The software package Stata v14.1 (StataCorp LP, College Station, TX, USA) was used for statistical analysis using Pearson's chi-square test or Fisher's exact test as appropriate, with a $p$-value of less than 0.05 as the threshold of statistical significance.

\section{Results}

The response rate was $38.5 \%$ (questionnaires returned completed). The answers corresponding to the first part of the questionnaires are presented in Table 1 . Most of participating health professionals were physicians (93.4\%) aged over 46 years (63.7\%), who had been working for more than three years in a vaccination center (80.2\%) (Table 1). Center East (Rhône-Alpes region - 22\%) and Ile-de-France (Paris area - 17.6\%) were the most represented areas in contrast with the North (4.4\%) and Center (5.5\%) areas (Table 1).

Answers corresponding to the second part of the questionnaires are presented in Table 2 . Most participating health professionals performed less than $50 \mathrm{JE}$ vaccinations per year (65.9\%) (Table 2). Those who had been working for more than 10 years in a vaccination center performed more than $30 \mathrm{JE}$ vaccinations per year (54.8\%). The proportion of health professionals performing more than $50 \mathrm{JE}$ vaccinations per year was higher in mainland France 
than in the overseas regions ( $p<0.05$, Fisher's exact test). Most participants declared that they were not reluctant to perform JE vaccinations (89\%). Causes of reluctance mentioned by participants were primarily the vaccine cost (80\%) and the difficulty to properly assess the risk for patients (20\%). Patient's refusal of JE vaccination was estimated as rare by $63.7 \%$ of participants (Table 2). The statistical analysis did not show any significant differences between geographical area and patient's refusal. Most participants declared using the rapid protocol for JE vaccination (D0 + D7) (75.8\%). The statistical analysis revealed that participants practicing in the overseas regions used the rapid protocol significantly less than participants practicing in mainland France ( $p<0.05$, Fisher's exact test). More than half of participating health professionals (58.2\%) declared using a booster vaccine and, for most of them, one year after the first vaccination (90.6\%). Eleven per cent of participants reported adverse events. Most participating health professionals suggest JE vaccination to people travelling to South Asia (99\%) and China (72.5\%). Most participants also declared taking into account the type of travel (97.9\%), backpacking being the riskiest (98.9\%) (Figure 1). A high proportion of participants said that they proposed JE vaccination all year round (72.5\%). The questionnaire included a concrete case of a patient sightseeing for two weeks in June in Thailand, and sleeping at local people's home: $75.8 \%$ of participating health professionals declared that they would not propose JE vaccination to such patients.

\section{Discussion}

The aim of this observational survey was to investigate how French health professionals working in vaccination centers used the JE vaccination. The response rate of $38.5 \%$ was satisfactory and close to those obtained in other studies based on sending questionnaires by 
regular mail to family physicians [6-8]. The use of questionnaires sent by email offered the opportunity to easily target all regions of France, including the overseas regions.

Few significant statistical differences in practice were observed in the present study. One of them was the higher proportion of health professionals prescribing the JE vaccination in mainland France as compared with the overseas regions. Little data on the size and number of vaccination centers in mainland France is available to accurately interpret this result. An hypothesis could be that health professionals in mainland France tend to propose the JE vaccination more systematically.

Globally, this study highlighted that a large majority of participating health professionals were favorable to the JE vaccination. However, the cost of the vaccine is a limitation. A study analyzing reasons for refusal of recommended travel-related vaccines in American travelers revealed that $35 \%$ of those who refused JE vaccination were concerned about cost [9]. In France, the cost of an injection of the JE vaccine is estimated at around 100 euros, which makes it one of the most expensive vaccines (the yellow fever vaccine costs about 70 euros; type A hepatitis, typhoid fever, rabies as well as meningococcal vaccines cost around 50 euros) [10]. Another practice difference concerned the rapid protocol (D0 + D7), significantly less frequently used in overseas regions than in mainland France. One hypothesis could be that travelers from mainland France do not seek information from vaccination centers early enough before the date of their departure, leaving the rapid protocol as the only option. Although participating health professionals seemed to be aware that South Asia is endemic for JE, they do not consider India as a country at risk for JE as often as the other countries of this area. It is worth noting that India is regularly affected by outbreaks. Backpacking was considered by participating health professionals as a major risk factor for JE exposure. However, recent publications warned that business travelers should also be considered at risk 
of being exposed to JE, especially as business meetings are no longer organized exclusively in urban areas but also in peri-urban locations $[11,12]$. This shift increases the risk of JE exposure. A high proportion of participants used the vaccination even if a trip was not planned during the rainy season; indeed, the risk of JE is observed all year round in tropical regions [12]. The concrete case proposed in the questionnaire tried to simulate a common situation encountered by health professionals in their practice as Thailand is a highly touristic country. From 1992 to $2012,43.6 \%$ of identified JE cases were acquired during travel to South Asia, and especially to Thailand [13].

The concrete case, for which most participants would not have proposed the JE vaccine, illustrates the difficulty encountered by health professionals when assessing risks. Contracting JE while traveling in Asia is rare. Travelers are 10 times less likely to contract JE when travelling than meningococcal meningitis while living in the United States [14]. Moreover, the risk is low, especially without exposure to mosquito bites at night (camping, trekking). Assessing the risk of exposure is a delicate issue for health professionals who are responsible for implementing the current recommendations for JE vaccination. Travelers are exposed to many other diseases (malaria, dengue, typhoid fever, etc.) and non-infectious risks (e.g., cardiovascular risks), which are more frequent and common than JE. This explains why prioritizing risks cannot be avoided and also why the JE vaccination is underused.

\section{Conclusion}

The unpredictability of the epidemiology, the very low incidence of JE in travelers, and the high cost of the vaccine do not facilitate risk assessment and compliance with the current recommendations for JE vaccination among health professionals. 


\section{References}

1.Campbell GL, Hills SL, Fischer M, Jacobson JA, Hoke CH, Hombach JM et al. Estimated global incidence of Japanese encephalitis: a systematic review. Bull World Health Organ 2011;89:766e-74e.

2.Hills SL, Griggs AC, Fischer M. Japanese encephalitis in travelers from non-endemic countries, 1973-2008. Am J Trop Med Hyg 2010;82:930-6.

3. Fischer M, Lindsey N, Staples JE, Hills S; Centers for Disease Control and Prevention (CDC). Japanese encephalitis vaccines: recommendations of the Advisory Committee on Immunization Practices (ACIP). MMWR Recomm Rep 2010;59:1-27.

4.Encéphalite japonaise - Haut Conseil de la santé publique, 2009. https://www.hcsp.fr/explore.cgi/avisrapportsdomaine?clefr=381 (accessed on April 4, 2018). 5. Bozon F, Parolini M, De Gentile L, Faucher JF, Chirouze C.[Vaccination antiamarile du voyageur de plus de 60 ans]. Poster TROP-06, Lille, JNI, juin 2016.

6. Jeanpetit R, Bellanger AP, Piotte E, Haffner-Mauvais C, Marguet P. Knowledge, attitudes and practices of primary care physicians in the Franche-Comte region (France) regarding the risk of rabies. Zoonoses Public Health 2014;6:371-6.

7. Bourgeois B, Marguet P, Gbaguidi-Haore H, Knapp J, Said-Ali Z, Demonmerot F, et al. Alveolar echinococcosis: how knowledgeable are primary care physicians and pharmacists in the Franche-Comté region of France?Acta Parasitol 2015;60:682-90.

8. Piotte E, Bellanger AP, Piton G, Millon L, Marguet P. Pre-travel consultation: evaluation of primary care physician practice in the Franche-Comté region. J Travel Med. 2013;20:221-7.

9. Lammert SM, Rao SR, Jentes ES, Fairley JK, Erskine S, Walker AT, et al. Refusal of recommended travel-related vaccines among U.S. international travellers in Global TravEpiNet. J Travel Med 2016;24(1). 
10.Pasteur Institute. Cost of vaccine per injection. Available at https://www.pasteur.fr/sites/default/files/rubrique_centre_medical/infos_pratiques/tarifs_ affiche-cm-institutpasteur_2017.pdf (accessed on April 4, 2018)

11. Deshpande BR, Rao SR, Jentes ES, Hills SL, Fischer M, Gershman MD, et al. Global TravEpiNet Consortium. Use of Japanese encephalitis vaccine in US travel medicine practices in Global TravEpiNet. Am J Trop Med Hyg 2014;91:694-8.

12. Connor B, Bunn WB. The changing epidemiology of Japanese encephalitis and New data: the implications for New recommendations for Japanese encephalitis vaccine. Trop Dis Travel Med Vaccines 2017;3:14.

13. Pavli A, Maltezou HC. Travel-acquired Japanese encephalitis and vaccination considerations. J Infect Dev Ctries 2015;9:917-24.

14. Shlim DR, Solomon T. Japanese encephalitis vaccine for travelers: exploring the limits of risk. Clin Infect Dis 2002;35:183-8. 
Figure 1. Types de voyages pour lesquels la vaccination était proposée

Figure 1. Types of travel considered for JE vaccination

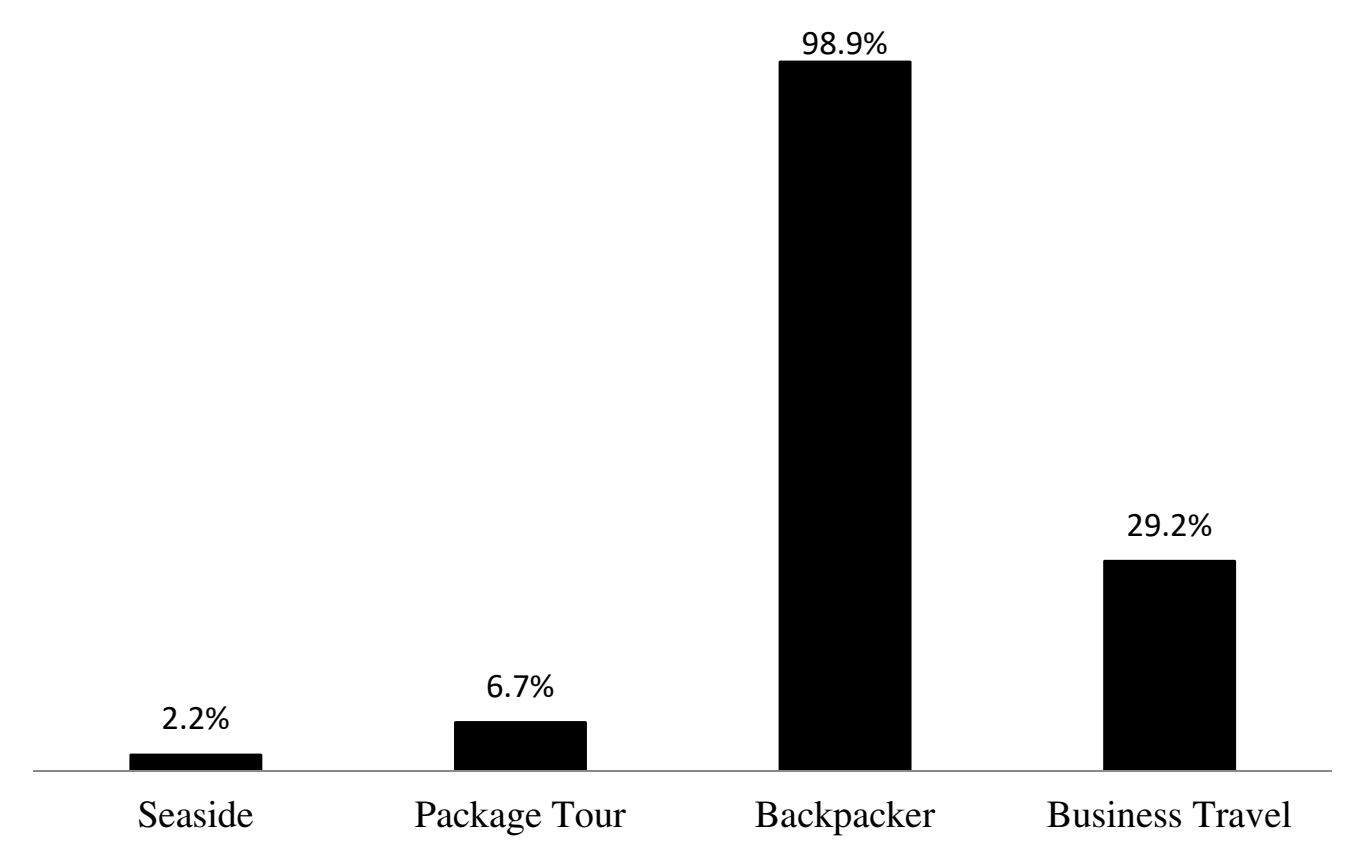


Table 1. Geographical and demographical distribution of participating health professionals.

Tableau 1. Répartition géographique et démographique des professionnels de santé ayant participé à l'étude.

\begin{tabular}{|c|c|c|}
\hline French geographical area & Number & $\%$ \\
\hline Center & 5 & 5.5 \\
\hline Center East & 20 & 22 \\
\hline North & 4 & 4.4 \\
\hline Northeast & 7 & 7.6 \\
\hline Northwest & 10 & 11 \\
\hline Ile-de-France (Paris area) & 16 & 17.6 \\
\hline Southeast & 10 & 11 \\
\hline Southwest & 10 & 11 \\
\hline French overseas territories & 9 & 9.9 \\
\hline \multicolumn{3}{|l|}{ Sex } \\
\hline Male & 42 & 46.1 \\
\hline Female & 49 & 53.9 \\
\hline \multicolumn{3}{|l|}{ Age } \\
\hline$<35$ years & 16 & 17.5 \\
\hline $36-45$ years & 17 & 18.8 \\
\hline $46-55$ years & 32 & 35.2 \\
\hline$>56$ years & 26 & 28.5 \\
\hline \multicolumn{3}{|c|}{ Duration of practice in a vaccination center } \\
\hline Less than 3 years & 18 & 19.8 \\
\hline Between 3 and 10 years & 31 & 34 \\
\hline More than 10 years & 42 & 46.2 \\
\hline \multicolumn{3}{|l|}{ Profession } \\
\hline Physician & 85 & 93.4 \\
\hline Nurse & 6 & 6.5 \\
\hline
\end{tabular}


Table 2. JE vaccination practice of participating health professionals.

Tableau 2. Pratiques vaccinales des participants concernant la vaccination contre l'encéphalite japonaise.

\begin{tabular}{ll}
\hline How many JE vaccinations do you perform per year? & $\%$ \\
\hline$<10$ & 25.2 \\
$10-30$ & 26.4 \\
$30-50$ & 14.3 \\
$50-100$ & 9.9 \\
$>100$ & 24.2
\end{tabular}

Are you reluctant to perform JE vaccination?

\begin{tabular}{ll}
\hline Yes & 11 \\
\hline No & 89 \\
\hline How often do you see people refusing the JE vaccination? & \\
\hline Never & 9.9 \\
\hline Rarely & 63.7 \\
\hline Frequently & 26.4 \\
\hline Do you use the rapid protocol (D0 +D7)? & \\
\hline Yes & 75.8 \\
\hline No & 24.2 \\
\hline Do you propose a booster vaccine? & \\
\hline Yes & 58.2 \\
\hline No & 41.8 \\
\hline Have you observed any adverse events? & \\
\hline Yes & 11 \\
\hline No & 89 \\
\hline For which destination do you easily prescribe the JE vaccination? & \\
\hline India & 51.6 \\
\hline Japan and the Philippines & 53.9 \\
\hline South Asia & 99 \\
\hline China & 72.5 \\
\hline Polynesia & 2.2 \\
\hline & \\
\hline
\end{tabular}




\begin{tabular}{ll}
\hline Do you take into consideration the type of travel? & 97.9 \\
Yes & 2.1 \\
\hline No & \\
\hline Do you recommend a JE vaccination when the travel/trip does not & \\
take place during the rainy season? & 72.5 \\
\hline Yes & 27.5 \\
\hline No & \\
\hline Concrete case: would you recommend JE vaccination for a patient & \\
traveling to Thailand for two weeks in June, knowing that he/she will & \\
be sightseeing and sleeping at local people's home? & 75.8 \\
\hline Yes & 24.2 \\
\hline No & \\
\hline
\end{tabular}

